\title{
Fluoroquinolone Resistance among Salmonella enterica Serovar Typhi and Paratyphi Isolates in a Tertiary Care Hospital in Northern India
}

\author{
${ }^{1}$ Deepinder Kaur, ${ }^{2}$ Rama Gupta, ${ }^{3}$ Omesh Goyal, ${ }^{4}$ Rajoo S Chhina
}

\begin{abstract}
Background and objectives: Enteric fever, caused by Salmonella enterica serovar S. Typhi and enterica serovar Paratyphi A, B and C is a major health problem worldwide. A progressive increase in antibiotic resistance has been reported among these organisms recently. This study aimed to estimate the prevalence of fluoroquinolone resistance among $\mathrm{S}$. Typhi and S. Paratyphi isolates from a tertiary care hospital in northern India.
\end{abstract}

Materials and methods: This retrospective study included Salmonella isolates obtained from the blood samples received in microbiology laboratory from January to December 2017. Blood specimens were processed using an automated blood culture system (BACTEC 9240/Bac-T-Alert). Antimicrobial susceptibility testing to ciprofloxacin and levofloxacin was performed using a fully automated Vitek-2 system.

Results: A total of 376 Salmonella enterica isolates were obtained; 294 (78.2\%) were identified as S. Typhi, and 82 (21.8\%) as S. Paratyphi A. Incidence of ciprofloxacin-resistant strains of S. Typhi was $67.3 \%$ and that of S. Paratyphi A was $97.6 \%$. Another $32.6 \%$ of S. Typhi and $2.4 \%$ S. Paratyphi A isolates showed decreased susceptibility to ciprofloxacin (MICs $0.25-0.5 \mu \mathrm{g} / \mathrm{mL}$ ). For levofloxacin, $25.8 \%$ of S. Typhi and $51.2 \%$ of S. Paratyphi A were resistant. Another $73.5 \%$ of S. Typhi and $48.8 \%$ of S. Paratyphi A isolates showed decreased susceptibility to levofloxacin (MICs $0.25-1 \mu \mathrm{g} / \mathrm{mL}$ ).

Interpretation and conclusion: The incidence of S. Typhi and $S$. Paratyphi $A$ isolates showing resistance or reduced susceptibility towards fluoroquinolone is very high in northern India.

Keywords: Ciprofloxacin, Enteric fever, Levofloxacin, Salmonella.

How to cite this article: Kaur D, Gupta R, Goyal O, Chhina RS. Fluoroquinolone Resistance among Salmonella enterica Serovar Typhi and Paratyphi Isolates in a Tertiary Care Hospital in Northern India. J Gastrointest Infect 2018;8(1):12-15.

${ }^{1}$ Professor and Head, ${ }^{2,3}$ Associate Professor, ${ }^{4}$ Dean Academics and Professor

1,2Department of Microbiology, Dayanand Medical College and Hospital, Ludhiana, Punjab, India

${ }^{3,4}$ Department of Gastroenterology, Dayanand Medical College and Hospital, Ludhiana, Punjab. India

Corresponding Author: Rajoo S Chhina, Dean Academics and Professor, Department of Gastroenterology, Dayanand Medical College and Hospital, Ludhiana, Punjab, India, e-mail: drrajoosingh@gmail.com
Source of support: Dayanand Medical College and Hospital, Ludhiana, Punjab

Conflict of interest: None

\section{INTRODUCTION}

Enteric fever, i.e., typhoid fever caused by Salmonella enterica serovar Typhi and paratyphoid fever caused by S. enterica serovar Paratyphi A, B, and C, is an important communicable disease of the underdeveloped countries. ${ }^{1-3}$ A prevalence of approximately 21 million cases has been reported worldwide with a mortality of about 222,000 deaths, annually. In India the disease is highly endemic with morbidity ranging from 102-2219 per 1 lakh inhabitants. ${ }^{4}$ Antibiotic are the cornerstone of management of enteric fever, which reduces the mortality from 30 to $<1 \%$. 5

Since 1989, there have been many published reports on multidrug-resistant (MDR) S. Typhi from India and other subcontinents. ${ }^{7-9}$ Multidrug-resistant S. Typhi is defined as resistance to chloramphenicol, co-trimoxazole, and ampicillin, which were used as first-line therapy for the treatment of enteric fever. Since then, the efficacy of other antibiotics including, fluoroquinolones and cephalosporins have been tested for the treatment of enteric fever. ${ }^{10,11}$ During the early 1990s, S. Typhi and S. Paratyphi including MDR strains were highly susceptible to fluoroquinolones and were used as an alternative treatment of enteric fever caused by. However, during the past decade, a significant increase in the minimum inhibitory concentration (MIC) of ciprofloxacin has been reported leading to clinical failure. ${ }^{12-17}$

Data on the drug resistance pattern of S. enterica from our region is limited. The present study was undertaken to evaluate the extent of S. Typhi, and S. Paratyphi isolates with reduced susceptibility/resistance towards fluoroquinolones.

\section{MATERIALS AND METHODS}

This was a retrospective analysis of the Salmonella isolates obtained from the blood samples received in Microbiology laboratory from January-December 2017. The Institutional ethics committee approved the study. 
All the blood specimens were processed using the automated blood culture system (BACTEC 9240, BD, India/ Bac-T-Alert, Biomerieux, USA). Samples were inoculated in blood culture bottles and incubated in the system. When the bottle was flagged positive by the system, a Gram staining was done from the bottle content. Next, subculture was done on $5 \%$ sheep blood agar and MacConkey agar. The isolates were identified and their antimicrobial susceptibility testing was performed using a fully automated Vitek-2 system. The turbidity of the bacterial suspension was adjusted with VITEK Densichek (BioMérieux, USA) to match the McFarland 0.5 standard in $0.45 \%$ sodium chloride. For identification of the isolates, VITEK 2 GNB ID cards were used, and for antibiotic susceptibility testing, VITEK 2 AST-N281 cards were used. All the isolates were further confirmed by serotyping.

The Clinical and Laboratory Standards Institute (CLSI) 2017 guidelines were used to interpret the susceptibility of S. Typhi and S. Paratyphi A. For ciprofloxacin, S. enterica isolates with a MIC of $<0.06 \mu \mathrm{g} / \mathrm{mL}$ were considered susceptible, between $0.12-0.5 \mu \mathrm{g} / \mathrm{mL}$ as intermediate susceptible and a MIC of $>1 \mu \mathrm{g} / \mathrm{mL}$ were considered as resistant. Similarly, for levofloxacin, the isolates with a MIC of $<0.12 \mu \mathrm{g} / \mathrm{mL}$ were considered susceptible, between $0.25-1 \mu \mathrm{g} / \mathrm{mL}$ as intermediate susceptible, whereas a MIC of $>2 \mu \mathrm{g} / \mathrm{mL}$ was considered as resistant. However, the calling range of Vitek 2 compact for ciprofloxacin is $0.25-4 \mu \mathrm{g} / \mathrm{mL}$, and that of levofloxacin is 0.125 to $8 \mu \mathrm{g} / \mathrm{mL}$.

\section{RESULTS}

A total of 376 S. enterica isolates were obtained; 294 isolates (78.2\%) were identified as S. Typhi, and $82(21.8 \%)$ were identified as S. Paratyphi A. Using the recommended breakpoints (CLSI), for ciprofloxacin, S. enterica isolates with a MICs of $\leq 0.06,0.125$ to 0.5 and $\geq 1 \mu \mathrm{g} / \mathrm{mL}$ were

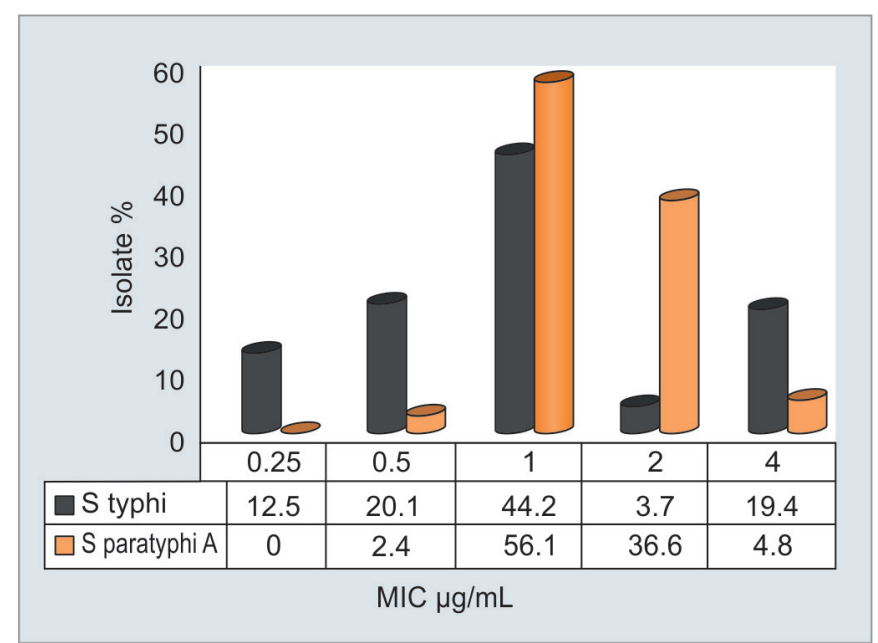

Graph 1: Distribution of S. Typhi $(n=294)$ and S. Paratyphi A $(n=82)$ isolates according to MIC $(\mu \mathrm{g} / \mathrm{mL})$ of ciprofloxacin treated as susceptible, intermediately susceptible and resistant respectively. The incidence of ciprofloxacin-resistant among S. Typhi isolates was $67.3 \%$ and $97.6 \%$ in case of S. Paratyphi A. Another $32.6 \%$ of S. Typhi and $2(2.4 \%)$ S. Paratyphi A isolates showed a MICs of $0.25-0.5 \mu \mathrm{g} / \mathrm{mL}$, hence were less susceptibility to ciprofloxacin (Graph 1). As per recommended breakpoints of ciprofloxacin, the isolates with MICs from $1-\geq 4.0 \mathrm{\mu g} / \mathrm{mL}$ taken as resistant. In the present study $19.4 \%$ ciprofloxacin-resistant isolates, had a MIC of $\geq 4.0 \mu \mathrm{g} / \mathrm{mL}$.

Taking into consideration the CLSI recommended breakpoints for levofloxacin against S. enteric, (MICs of $\leq 0.125,0.25-1$ and $\geq 2 \mu \mathrm{g} / \mathrm{mL}$ indicated susceptibility, intermediate susceptibility, and resistance respectively), $25.8 \%$ S. Typhi isolates and $51.2 \%$ of S. Paratyphi A isolates were found to be resistant to levofloxacin. Another $73.5 \%$ of S. Typhi and $48.8 \%$ of S. Paratyphi A isolates were observed with decreased sensitivity towards levofloxacin with a MICs from $0.25-1 \mu \mathrm{g} / \mathrm{mL}$. Only $0.68 \%$ of S. Typhi isolates showed a MIC of $\leq 0.12 \mu \mathrm{g} / \mathrm{mL}$, hence were susceptible to levofloxacinan MIC. However, none isolate of the S. Paratyphi A isolate was sensitive to levofloxacin. Table 1 depicts the susceptibility of ciprofloxacin and levofloxacin towards S. Typhi and S. Paratyphi A.

Table1: Susceptibility pattern of S. Typhi $(n=294)$ and S. Paratyphi A $(n=82)$ isolates towards ciprofloxacin and levofloxacin

\begin{tabular}{|c|c|c|}
\hline Susceptibility pattern & $\begin{array}{l}\text { S. Typhi } \\
n(\%)\end{array}$ & $\begin{array}{l}\text { S. Paratyphi A } \\
n(\%)\end{array}$ \\
\hline \multicolumn{3}{|l|}{ Ciprofloxacin } \\
\hline $\begin{array}{l}\text { (i) Intermediate (MIC } \leq 0.25-0.5 \\
\mu \mathrm{g} / \mathrm{ml} \text { ) }\end{array}$ & $96(32.6 \%)$ & $2(2.4 \%)$ \\
\hline (ii) Resistant (MIC $\geq 1 \mu \mathrm{g} / \mathrm{mL}$ ) & $198(67.3 \%)$ & $80(97.6 \%)$ \\
\hline \multicolumn{3}{|l|}{ Levofloxacin } \\
\hline (i) Sensitive (MIC $\leq 0.12 \mu \mathrm{g} / \mathrm{mL}$ ) & $2(0.68 \%)$ & 0 \\
\hline $\begin{array}{l}\text { (ii) Intermediate (MIC 0.25-1 } \\
\mu \mathrm{g} / \mathrm{mL} \text { ) }\end{array}$ & $216(73.5 \%)$ & $40(48.8 \%)$ \\
\hline (iii) Resistant (MIC $\geq 2 \mu \mathrm{g} / \mathrm{mL}$ ) & $76(25.8 \%)$ & $42(51.2 \%)$ \\
\hline
\end{tabular}
$\mathrm{MIC}=$ minimal inhibitory concentration

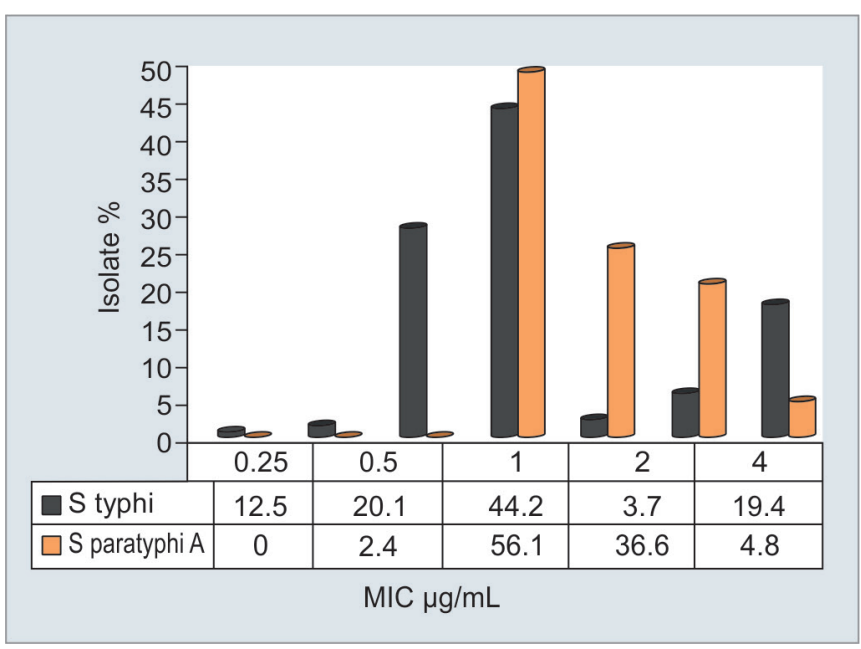

Graph 2: Distribution of S. Typhi $(n=294)$ and S. Paratyphi A $(n=82)$ isolates according to MIC $(\mu \mathrm{g} / \mathrm{mL})$ of levofloxacin 
Table 2: Drug resistance profile of S. Typhi $(n=294)$ and S. Paratyphi A $(n=82)$ isolates*

\begin{tabular}{lll}
\hline & $\begin{array}{l}\text { S. Typhi } \\
n(\%)\end{array}$ & $\begin{array}{l}\text { S. Paratyphi } \\
n(\%)\end{array}$ \\
\hline Cotrimiotics & $17(5.8)$ & $3(3.7)$ \\
Ceftazidime & $15(5.1)$ & $2(2.4)$ \\
Ceftriaxone & $9(3.1)$ & $2(2.4)$ \\
Cefuroxime & $5(1.7)$ & $2(2.4)$ \\
Cefepime & $10(3.4)$ & $1(1.2)$ \\
\hline
\end{tabular}

Graph 2 depicts the observed MIC of levofloxacin against S. Typhi and S. Paratyphi A isolates. Levofloxacinresistant $\mathrm{S}$. enteric isolates showed a MIC ranging from 2 to $\geq 8.0 \mu \mathrm{g} / \mathrm{mL}$. Approximately $18 \%$ of $S$. Typhi and $4.9 \%$ of S. Paratyphi A isolates showed AN MIC of $\geq 8.0 \mu \mathrm{g} / \mathrm{mL}$. The drug resistance profile of $S$. Typhi $(n=294)$ and $S$. Paratyphi A ( $\mathrm{n}=82)$ isolates for other commonly used antibiotics is shown in Table 2.

\section{DISCUSSION}

Enteric fever is a systemic disease caused by contaminated water with S. Typhi and S. Paratyphi. It is characterized by high fever, pain abdomen and loss of appetite. Despite significant improvement in the sanitary conditions, it is one of important public health problem with millions of people suffer from the disease with a mortality of nearly $30 \%$. $^{1-3,18}$

About three decades back, chloramphenicol was the drug of choice for the treatment for enteric fever, while ampicillin and co-trimoxazole were good alternatives. With the emergence of MDR S. Typhi and S. Paratyphi A alternatives for the treatment of enteric fever were continuously looked into. With due course of time and availability of data, fluoroquinolones became the first line drug for the treatment of enteric fever, specifically against MDR strain. ${ }^{19,20}$ The guidelines from Association of Physicians of India, published in 2015, also recommend fluoroquinolones as one of the first lines treatment. ${ }^{21}$

However, more recently, many studies from all over the world have reported increasing resistance to fluoroquinolones. ${ }^{22-30}$ Many reports have been published showing an alarmingly high incidence of S. Typhi isolates with reduced susceptibility of ciprofloxacin (MIC $\geq 0.125 \mu \mathrm{g} / \mathrm{mL}) .{ }^{21,22}$ A report from the United Kingdom emphasized that the extent of S. Typhi isolates with reduced ciprofloxacin susceptibility had an increase from $0.9-33 \%$ during 1991 to $1999 .{ }^{24}$ Similar trends were reported from Japan during the year 19971999, where an increase from 10-31.8\% was observed. A large number of studies had also reported an increase in the enteric fever cases of clinical treatment failures with ciprofloxacin and other fluoroquinolones. ${ }^{23-25}$ In a recent study by Sharma et al., ${ }^{27}$ ciprofloxacin, ofloxacin and levofloxacin susceptibility were $71.3 \%, 70.8 \%$ and $70.9 \%$ for S. Typhi and $58.1 \%, 57.4 \%$ and $57.1 \%$ for S. Paratyphi A, respectively. In a study on the longitudinal typhoid fever trends in India from 2000 to 2015, it was reported that initially ciprofloxacin resistance ranged from $1-26 \%$, and in more recent testing, resistance rose to $98 \%$, using the revised CLSI 2012 guidelines interpretative criteria. Of all the antimicrobials tested, ceftriaxone was the most active agent, with resistance rates of about $1.5-4 \%$. Cefixime resistance was also very low at $0.2-2 \%$, reported in only one study from India. ${ }^{28}$ Another study from Nepal has reported, clinical failure in $26 \%$ of the enteric fever patients put on gatifloxacin. However, with ceftriaxone, only $7 \%$ failed treatment. ${ }^{29}$ In a systematic review of the data available from Asian countries, Britto et al. ${ }^{30}$ have reported that $60 \%$ of the $S$. Typhi isolates were fluoroquinolone resistant. The most common mechanisms responsible for fluoroquinolone resistance include mutations in QRDRs in gyr $A(\mathrm{~S} 83 \mathrm{~F}$, D87N) and par C (S80I). A study by Vaishnavi et al. ${ }^{31}$ reported that $\mathrm{Vi}$ serology employing highly purified $\mathrm{Vi}$ antigen offered a practical and cost-effective way of screening for S. Typhi carriers. In the present study, we observed that the large number of S. Typhi and S. Paratyphi A isolates not only have decreased susceptibility (intermediate susceptible) towards both the fluoroquinolones tested, but there is a huge number of isolates showing resistance against fluoroquinolones with very high MIC values. An alarmingly high number, i.e. $67.3 \%$ of S. Typhi and $97.6 \%$ of S. Paratyphi A isolates were found resistant to ciprofloxacin. Another 32.6\% of S. Typhi and $2(2.4 \%)$ S. Paratyphi A isolates were found to have reduced susceptibility to ciprofloxacin. $19.4 \%$ of the ciprofloxacin-resistant isolates had a very high MIC of $\geq 4.0 \mu \mathrm{g} / \mathrm{mL}$. However, ciprofloxacin concentration range on the AST-GN281 card is 0.25 to $4 \mu \mathrm{g} / \mathrm{mL}$, which does not include differentiation of susceptible and intermediate susceptible (MIC $\leq 0.25$ $\mu \mathrm{g} / \mathrm{mL}$ ) isolates of Salmonella, as the susceptible MIC is $\leq 0.0625 \mu \mathrm{g} / \mathrm{mL}$ as per CLSI. Only $12.5 \%$ of the $S$. Typhi isolates had a MIC $\leq 0.25 \mu \mathrm{g} / \mathrm{mL}$ and fall in this category. On the contrary, none of the S. Paratyphi A isolates fall in this group. Similar results were observed with levofloxacin, as none of the $S$. Paratyphi A found susceptible to levofloxacin. A very high levofloxacin MIC of $\geq 8.0 \mu \mathrm{g} / \mathrm{mL}$ was observed in $4.9 \%$ (4/82) of $S$. Paratyphi A strains.

To conclude, a number of cases of enteric fever with fluoroquinolone-resistant/reduced fluoroquinolone susceptibile S. Typhi and S. Paratyphi A isolates were found to be alarmingly high. The clinicians should be made aware of the facts time to time to prevent complications and clinical failure. 


\section{REFERENCES}

1. Arora RK, Gupta A, Joshi NM, Kataria VK, Lall P, Anand AC. Multidrug resistant typhoid fever: study of an outbreak in Calcutta. Indian pediatrics. 1992 Jan;29(1):61-66.

2. Zavala Trujillo I, Quiroz C, Gutierrez MA, Arias J and Renteria M. Fluoroquinolones in the treatment of typhoid fever and the carrier state. Eur J ClinMicrobiol Infect Dis 1991;10:334-341.

3. Arora D, Singh R, Kaur M, Ahi RS. A changing pattern in antimicrobial susceptibility of Salmonella enterica serotype isolated in North India. African J Microbiol Res 2010;4(3):197-203.

4. Mehta PJ, Hakim A, Kamath S. The changing faces of salmonellosis. J Assoc Physicians India. 1992;40:713-715.

5. Kanungo S, Dutta S, Sur D. Epidemiology of typhoid and paratyphoid fever in India. J Infect Dev Ctries 2008;2:454460.

6. Capoor MR, Nair D, Hasan AS, Aggarwal P, Gupta B. Typhoid fever: Narrowing therapeutic options in India. Southeast Asian J Trop Med Public Health 2006;37:1170-1174.

7. Jesudason M V, Jacob John T. Multi-resistant Salmonella typhi in India. Lancet 1990;336:252.

8. Threlfall E J, Ward L R, Rowe B, Raghupathi S, Chandrasekaran V, Vandepitte J, et al. Widespread occurrence of multiple drug-resistant Salmonella typhi in India. Eur J ClinMicrobiol Infect Dis 1992;11:990-993.

9. Pang T, Bhutta Z A, Finlay B B, Altwegg M. Typhoid fever and other salmonellosis: a continuing challenge. Trends Microbiol 1995;3:253-255.

10. Gulati S, Marwaha R K, Singhi S, Ayyagari A, Kumar L. Third generation cephalosporins in multi-drug resistant typhoid fever. Indian Pediatr 1992;29:513-516.

11. Mathai D, Kudwa G C, Keystone J S, Kozarsky P E, Jesudason M V, Lalitha M K,et al. Short course of ciprofloxacin in enteric fever. J Assoc Physicians India 1993;41:7428-7430.

12. Mehta A, Rodriques C, Joshi VR. Multiresistant Salmonella organisms in India. JAMA 1992;267:1614-1615.

13. Umasankar S, Wall RA, Berger J. A case of ciprofloxacinresistant typhoid fever. Commun Dis Rep CDR Rev 1992; 2:R139-140.

14. Chandra R, Srinivasan S, Nalini P, Rao S. Multidrug resistant enteric fever. J Trop Med Hyg 1992;95:284-287.

15. Biswal N, Mathai B, Bhatia BD, Srinivasan S. Use of ciprofloxacin and its resistance in typhoid fever. Indian Pediatr 1994; 31:229-230.

16. Daga MK, Sarin K, Sarkar R. A study of culture positive multidrug resistant enteric fever-changing pattern and emerging resistance to ciprofloxacin. J Assoc Physicians India 1994; 42:599-600.

17. Rowe B, Ward LR, Threlfall EJ. Ciprofloxacin-resistant Salmonella typhi in the UK. Lancet 1995;346:1302.
18. Gautam V, Gupta NK, Chaudhary U, Arora DR. Sensitivity pattern of Salmonella serotypes in Northern India. Braz J Infect Dis. 2002;6:281-287.

19. Hirose K, Tamura K, Sagara H, Watanabe H. Antibiotic susceptibilities of Salmonella enterica Serovar Typhi and S. enterica Serovar Paratyphi A isolated from patients in Japan. Antimicrob Agents Chemother. 2001;45:956-958.

20. Asperilla MO, Smego RA Jr, Scott LK. Quinolone antibiotics in the treatment of Salmonella infections. Rev Infect Dis 1990; 12:873-889.

21. Upadhyay R, Nadka MY, Muruganathan A, Tiwaskar M, Amarapurkar D, Banka NH, et al. API Recommendations for the Management of Typhoid Fever. J Assoc Physicians India. 2015 Nov;63(11):77-96.

22. Brown NM, Millar MR, Frost JA, Rowe B. Ciprofloxacin resistance in Salmonella paratyphi A. J Antimicrob Chemother. 1994;33:1258-1259.

23. Divyashree S, Nabarro LE, Veeraraghavan B, Rupali P. Enteric fever in India: current scenario and future directions. Trop Med Int Health. 2016 Oct;21(10):1255-1262.

24. Threlfall EJ, Ward LR, Skinner JA, Smith HR, Lacey S. Ciprofloxacin resistant Salmonella typhi and treatment failure. Lancet 1999;353:1590-1591.

25. Wain J, Hoa NT, Chinh NT, Vinh H, Everett MJ, Diep TS, et al. Quinolone resistant Salmonella typhi in Vietnam: molecular basis of resistance and clinical response to treatment. Clin Infect Dis 1997;25:1404-1410.

26. Mermin JH, Villar R, Carpenter J, Roberts L, Samaridden A, Gasanova L,et al. A massive epidemic of multidrug-resistant typhoid fever in Tajikistan associated with consumption of municipal water. J Infect Dis. 1999;179:1416-1422.

27. Sharma P, Dahiya S, Manral N, Kumari B, Kumar S, Pandey $S$, et al. Changing trends of culture-positive typhoid fever and antimicrobial susceptibility in a tertiary care North Indian Hospital over the last decade. Indian J Med Microbiol 2018;36:70-76

28. Balaji V, Kapil A, Shastri J, Pragasam AK, Gole G, Choudhari S, et al. Longitudinal Typhoid Fever Trends in India from 2000 to 2015. Am J Trop Med Hyg. 2018 Sep;99(3_Suppl):34-40.

29. Arjyal A, Basnyat B, Nhan HT, Koirala S, Giri A, Joshi N, et al. Gatifloxacin versus ceftriaxone for uncomplicated enteric fever in Nepal: an open-label, two-centre, randomised controlled trial. Lancet Infect Dis. 2016 May;16(5):535-545.

30. Britto CD, Wong VK, Dougan G, Pollard AJ. A systematic review of antimicrobial resistance in Salmonella enterica serovar Typhi, the etiological agent of typhoid. PLoSNegl Trop Dis. 2018 Oct 11;12(10):e0006779.

31. Vaishnavi C, Kochhar R, Singh G, Kumar S, Singh S, Singh K. Epidemiology of typhoid carriers among blood donors and patients with biliary, gastrointestinal and other related diseases. MicrobiolImmunol. 2005;49(2):107-112. 